\title{
Epistemologia qualitativa, fenomenologia e pesquisa-ação: diálogos possíveis
}

\author{
Erikson de Carvalho Martins ${ }^{1}$ \\ Gilberto Lacerda dos Santos ${ }^{2}$
}

\section{Resumo}

Este artigo tem por objetivo identificar e discutir alguns encontros e desencontros existentes entre a epistemologia qualitativa, a fenomenologia e a pesquisa-ação, no que diz respeito à natureza, aos objetivos e procedimentos adotados. Nesse sentido, realizamos uma revisão teórica para identificar as características comuns e divergentes entre as categorias de pesquisa investigadas. Para tanto, buscamos as contribuições teóricas de González Rey (2003, 2006) acerca da teoria da subjetividade e de sua epistemologia qualitativa, de Moreira (2002) e seus estudos sobre a fenomenologia e, por fim, de Thiollent (2011), que apresenta as principais características da pesquisa-ação.

Palavras-chave: Epistemologia qualitativa; Fenomenologia; Pesquisa-ação.

\section{Abstract}

This article aims to identify and discuss some encounters and mismatches between qualitative epistemology, phenomenology and action research, regarding the nature, objectives and procedures adopted. In this context, we carried out a theoretical review with the registration production to identify common and divergent characteristics among the categories of the investigated research. For that, we seek the theoretical contributions of González Rey (2003, 2006) about the subjectivity theory and its qualitative epistemology, by Moreira (2002) and his studies on phenomenology, and finally on Thiollent (2011), which presents the main characteristics of action research.

Key Words: Qualitative Epistemology; Phenomenology; Action research.

\footnotetext{
${ }^{1}$ Professor de Língua Portuguesa do Instituto Federal de Educação, Ciência e Tecnologia da Bahia (IFBA, campus Barreiras), doutorando do Programa de Pós-Graduação em Educação da Universidade de Brasília (UnB), mestre em Letras pela Universidade do Estado da Bahia (UNEB).

2 Professor titular do Departamento de Métodos e Técnicas da Faculdade de Educação da Universidade de Brasília (UnB), líder do Grupo Ábaco de Pesquisas Interdisciplinares sobre Informática e Educação.
} 


\section{Introdução}

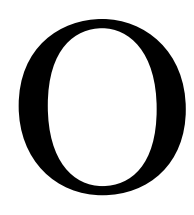

debate acerca da cientificidade das ciências humanas, tendo-se como referência a epistemologia das ciências naturais, não é novo. Nesse debate, encontram-se discussões sobre seus respectivos objetos de estudo, sobre as abordagens metodológicas que as caracterizam e sobre o sujeito e a influência do social em ambas as vertentes científicas.

De um lado, por muito tempo, as ciências humanas objetivaram a construção de novos conhecimentos tendo como base os tradicionais princípios, modelos e métodos científicos das ciências naturais, o que produziu uma gama de conhecimentos superficiais e até mesmo equivocados sobre diversos objetos até o desenvolvimento de procedimentos específicos para a produção de pesquisas na área. Do outro, as ciências naturais continuaram a se reafirmar como a "verdadeira ciência", desconsiderando métodos e abordagens empregados pelas ciências humanas e sociais e objetivando atingir um conhecimento completo e acabado.

Conforme Japiassu (1978), na busca de objetividade e de afirmação como ciência, o campo das ciências humanas nasceu copiando os modelos científicos das ciências positivas. Para tanto, abandonou, inicialmente, o caráter reflexivo e interpretativo da filosofia, buscando atingir a cientificidade das ciências naturais e sua forma de explicação dos fenômenos. Sanford (1899) corrobora o pensamento de Japiassu (1978) ao destacar que a batalha das ciências está na delimitação entre as ciências físicas/naturais e as ciências ditas como "espirituais ou mentais", o que hoje conhecemos como humanas e sociais. Para ele, a busca por métodos seguros na realização das pesquisas fez com que as ciências humanas e sociais utilizassem os métodos experimentais e quantitativos das ciências exatas e naturais, produzindo, assim, conhecimentos incertos.

Gamboa (2007) sinaliza que a efetivação de um trabalho de pesquisa com êxito está na realização de uma articulação lógica entre os elementos metodológicos e o conhecimento dos pressupostos e das implicações da abordagem epistemológica, evidenciando a relação existente entre as técnicas, métodos, paradigmas científicos, pressupostos gnosiológicos e 
ontológicos presentes em qualquer pesquisa científica. Infelizmente, segundo o autor, grande parte das pesquisas desenvolvidas ainda apresenta uma visão mecanicista de metodologia, descrevendo métodos e instrumentos, sem uma reflexão aprofundada sobre seus usos, pressupostos e consequências, o que muitas vezes é resultado da própria formação dos pesquisadores nos mais diversos programas de pós-graduação.

Hoje, quanto à abordagem, as pesquisas podem ser realizadas dentro de uma vertente qualitativa ou quantitativa, podendo, ainda, desenvolver estudos que sejam qualitativo-quantitativos. A abordagem qualitativa se caracteriza como um estudo aprofundado de uma dada realidade, procurando descrevêla, analisá-la, interpretá-la e compreendê-la, tendo em vista os fatos que ocorrem e todos os envolvidos nesse processo. Ela surge como uma oposição ao modelo unívoco de pesquisa para todas as ciências, visto que as ciências humanas e sociais possuem suas especificidades e utilizam metodologias e métodos que condizem com seus objetos e objetivos de estudo.

Dentro dessa abordagem qualitativa, observamos a existência de diversos tipos de pesquisa que variam conforme a natureza, os objetivos e os procedimentos adotados, como, por exemplo: a epistemologia qualitativa desenvolvida por González Rey, originalmente destinada ao estudo da subjetividade; a fenomenologia e o método fenomenológico, cujas raízes estão na filosofia e se destinam à busca das essências dos fenômenos, das experiências vivenciadas pelos sujeitos; e a pesquisa-ação, que é desenvolvida com uma estreita relação com a ação, objetivando a resolução de um problema coletivo a partir da integração, interação e participação ativa dos pesquisadores e sujeitos envolvidos.

Dado o exposto interesse pelas categorias apresentadas como alternativas de uma abordagem qualitativa de pesquisa, este trabalho busca responder ao seguinte questionamento: Quais os pontos de concordância e discordância existentes entre a epistemologia qualitativa, a fenomenologia e a pesquisa-ação? O estudo em torno dessa questão possui como objetivos identificar e discutir alguns encontros e desencontros existentes entre a epistemologia qualitativa, a fenomenologia e a pesquisa-ação, no que diz 
respeito à natureza, aos objetivos e procedimentos adotados. Como método de pesquisa realizamos uma revisão teórica com a produção de fichamentos para identificar as características comuns e divergentes entre os tipos de pesquisa investigados.

Este artigo está dividido em cinco momentos. Primeiramente, discutimos sobre a teoria da subjetividade e o desenvolvimento da epistemologia qualitativa de González $\operatorname{Rey}^{3}$ (2003, 2006). Em seguida, discorremos sobre a fenomenologia e o método fenomenológico a partir dos estudos realizados por Moreira ${ }^{4}$ (2002). Posteriormente, sintetizamos as características da pesquisa-ação nos estudos de Thiollent ${ }^{5}$ (2011). A seguir, apresentamos os encontros e desencontros entre as propostas de pesquisa elucidadas. Finalmente, tecemos nossas considerações sobre o valor dessas categorias de pesquisa para as investigações de abordagem qualitativa nas ciências humanas e sociais.

\footnotetext{
${ }^{3}$ Fernando Luís González Rey possui graduação em Psicologia - Universidad de La Habana (1973) e doutorado em Psicologia pelo Instituto de Psicologia Geral e Pedagógica de Moscou (1979). Pós-doutorado em Psicologia pelo Instituto de Psicologia da Academia de Ciências de Moscou (1987). Atualmente, é professor titular do Centro Universitário de Brasília. Foi professor visitante institucional da Universidade Autônoma de Madri (2004-2012), assim como professor e assessor do Programa de Doutorado em Psicologia da Universidad de San Carlos em Guatemala (2002-2012). Tem experiência na área de Psicologia, com ênfase em Psicologia Cultural-Histórica. Seu foco de atenção teórica é o desenvolvimento do tema da subjetividade numa perspectiva cultural-histórica e os problemas epistemológicos e metodológicos que se derivam do estudo da subjetividade.

${ }^{4}$ Daniel Augusto Moreira possui graduação em Engenharia Química pela Universidade de São Paulo (1969), mestrado em Engenharia (Engenharia de Produção) pela Universidade de São Paulo (1978) e doutorado em Educação pela Universidade de São Paulo (1986). Atualmente é professor da Universidade de São Paulo e professor titular do Centro Universitário Nove de Julho. Tem experiência na área de Administração, com ênfase em Analfabetismo Funcional, atuando principalmente nos seguintes temas: analfabetismo funcional, ensino e pesquisa em administração, produtividade, administração de empresas e administração.

${ }^{5}$ Michel Jean Marie Thiollent possui formação em Desenvolvimento Econômico e Social Institut d'Etude du Développement Économique et Social (1969) - graduação e mestrado Université de Paris I (Panthéon-Sorbonne) (1971) e Doutorado em Sociologia - Université de Paris V (René Descartes) (1975). Atualmente é professor Adjunto do PPGA - Programa de Pós-Graduação em Administração da UNIGRANRIO. Anteriormente foi professor associado 3 (aposentado) da Universidade Federal do Rio de Janeiro/COPPE. Ex-Professor de Sociologia do Instituto de Filosofia e Ciências Humanas da UNICAMP (1975-1980). Tem experiência nas áreas de Estudos Organizacionais e Metodologia de Pesquisa Qualitativa, atuando principalmente nos seguintes temas: pesquisa-ação, cooperação, métodos de pesquisa e de extensão.
}

\begin{tabular}{||c||}
\hline $\begin{array}{c}\text { Filosofia e Educação [RFE] - Volume 9, Número 3 - Campinas, SP } \\
\text { Outubro de 2017-Janeiro de 2018 - ISSN 1984-9605 - p. 18-45 }\end{array}$ \\
\hline
\end{tabular}




\section{A epistemologia qualitativa de González Rey}

A epistemologia qualitativa desenvolvida por González Rey constitui-se como uma ótica epistemológica e metodológica para os estudos e compreensão dos fenômenos complexos acerca da subjetividade humana, sendo hoje bastante utilizada em outras áreas de investigação que não se restringem especificamente à Psicologia, como nos campos da Educação, da Saúde e da Administração, por exemplo. Por essa razão, abordaremos inicialmente, de forma breve, alguns aspectos acerca da teoria da subjetividade desenvolvida pelo autor, adentrando, posteriormente, em sua epistemologia qualitativa.

Na teoria da subjetividade proposta por González Rey (2003), o ser humano é concebido como sujeito de pensamento, linguagem e emoção, caracterizando-se, assim, como sujeito participativo e reflexivo. Para ele, a participação e a reflexibilidade são características existenciais do ser humano, que compõem a sua subjetividade. Dentro de uma perspectiva históricocultural, González Rey (2003) entende que a subjetividade se constitui na dialética entre o individual e o social, em que o indivíduo está comprometido com o mundo à sua volta e desempenha um papel ativo em suas práticas sociais, reflexões e sentidos subjetivos. Nesse sentido, a cultura, o sujeito e a subjetividade se inter-relacionam e se integram continuamente, sendo o ser humano constituído pela cultura ao mesmo tempo que também a constitui, numa relação de recursividade.

González Rey (2006, p.38) define a subjetividade como:

un sistema complejo, capaz de expresar a través de una cualidad diferente: el sentido subjetivo, la diversidad de aspectos objetivos de la vida social que concurren en su formación. Este concepto nos permite trascender la taxonomía de categorías puntuales y fragmentadas que históricamente ha sido usada por la psicología para referirse a comportamientos concretos en diferentes esferas de la vida del sujeto. Tradicionalmente la división de los diferentes campos al interior de la psicología ha estado delimitada por el uso de categorías diferentes que, más que explicitar sistemas cualitativamente diferentes, han 
representado apenas la descripción de comportamientos concretos diferentes, específicos de actividades humanas también diferentes. La subjetividad como sistema nos permite trascender esta fragmentación, $\mathrm{y}$ representarnos un sistema cuyas unidades y formas principales de organización se alimentan de sentidos subjetivos definidos en diferentes áreas de la actividad humana, los cuales están interrelacionados entre sí. ${ }^{6}$

Tendo em vista o rompimento com a tradição psicológica de concepção da subjetividade como um fenômeno apenas individual, González Rey (2003) também utilizou a expressão subjetividade social, esclarecendo que os processos sociais não são externos aos indivíduos, mas fazem parte de um sistema complexo e plurideterminado em que o sujeito é constituído e constituinte, integrando, assim, o individual e o social.

Segundo Martínez, Conceição e Pereira (2016) a subjetividade, na teoria de González Rey, é constituída de sentidos subjetivos e configurações subjetivas. Os sentidos subjetivos são a união entre o simbólico e o emocional, novas produções em relação às experiências vivenciadas e que são indissociáveis da organização subjetiva dos sujeitos e dos muitos âmbitos de sua vida social. Os sentidos subjetivos não são captados nas expressões diretas dos sujeitos, como em uma frase por exemplo, mas são apreendidos de forma indireta por meio da localização de uma palavra num depoimento, na diferenciação entre o tratamento de temas, nas comparações entre diversas significações. Já por configurações subjetivas, entende-se a inter-relação dinâmica entre os diferentes sentidos subjetivos, é o teor das experiências

\footnotetext{
6 “"...] um sistema complexo, capaz de expressar através de uma qualidade diferente: o sentido subjetivo, a diversidade de aspectos objetivos da vida social que concorrem em sua formação. Esse conceito nos permite transcender a taxonomia de categorias pontuais e fragmentadas que historicamente têm sido usadas pela psicologia para se referir a comportamentos concretos em diferentes esferas da vida do sujeito. Tradicionalmente a divisão dos diferentes campos do interior da psicologia tem estado delimitada pelo uso de categorias diferentes que, mais que explicitar sistemas qualitativamente diferentes, tem representado apenas a descrição de comportamentos concretos diferentes, específicos de atividades humanas também diferentes. A subjetividade como sistema nos permite transcender essa fragmentação, e representarmos um sistema cujas unidades e formas principais de organização se alimentam de sentidos subjetivos definidos em diferentes áreas da atividade humana, os quais estão inter-relacionados entre si." (Tradução nossa).
}

\section{Filosofia e Educação [RFE] - Volume 9, Número 3 - Campinas, SP Outubro de 2017-Janeiro de 2018 - ISSN 1984-9605 - p. 18-45}


subjetivas que trazem sentidos subjetivos articulados com outros estados dinâmicos. (MARTÍNEZ, CONCEIÇÃO e PEREIRA, 2016).

As considerações expostas acerca da teoria da subjetividade, bem como a apresentação de alguns de seus conceitos importantes, como o de sentidos subjetivos e configurações subjetivas, dão-nos embasamento para discorrer sobre a epistemologia qualitativa, também idealizada por González Rey, como método epistemológico e metodológico para o estudo da subjetividade.

Consoante González Rey (2006), a sua proposta de epistemologia qualitativa para os estudos da subjetividade em sua complexidade está baseada em três princípios. O primeiro deles diz respeito ao caráter construtivo-interpretativo do conhecimento. De acordo com esse princípio, o conhecimento não é visto como uma apreensão da realidade dada, mas como um processo de construção, de produção humana constante. Nesse sentido, González Rey (2006) objetiva acabar com a distinção existente entre o teórico, muitas vezes visto como mera especulação, e o empírico, concebido como um atributo da realidade externa. Para ele, a produção da teoria se dá simultaneamente à realização das investigações empíricas, sendo, dessa forma, indissociáveis na construção do conhecimento.

O segundo princípio se refere à legitimação do singular como campo de produção do conhecimento. Sendo uma característica diferenciada de sua proposta, esse princípio evidencia o valor que se dá ao teórico no processo de investigação, sendo esse não apenas associado a informações preestabelecidas acerca do objeto de pesquisa, mas também associado à capacidade de reflexão do pesquisador nas atividades de investigação. Como assegura González Rey (2006, p.29),

lo teórico no se reduce a las teorías que constituyen fuentes de saber preexistentes en relación al proceso de investigación, sino que está referido, de forma muy particular, a los procesos de construcción intelectual que van acompañando a la investigación. Lo teórico se 
expresa en una procesualidad que tiene en su centro la actividad pensante y constructiva del investigador. ${ }^{7}$

Por sua vez, o terceiro princípio remete à compreensão das pesquisas nas ciências antropossociais como processos de diálogo e comunicação. González Rey (2006) esclarece que a comunicação é um âmbito importante para o estudo da subjetividade, visto que uma grande maioria dos problemas humanos e sociais está relacionada direta ou indiretamente ao processo dialógico. Por meio da comunicação é possível conhecer diferentes processos simbólicos que são organizados e recriados, bem como as representações e expressões conscientes dos protagonistas que se tornam sujeitos da pesquisa, demonstrando seus interesses, desejos e contradições. Assim, a comunicação é vista como um contexto essencial para o surgimento de sujeitos críticos e criativos no curso da investigação, valorizando o processo de produção de sentidos desses sujeitos investigados no desenvolvimento da pesquisa. (GONZÁLEZ REY, 2006).

González Rey (2006) sinaliza a importância da criação do cenário de pesquisa no processo de investigação. Para o autor, o cenário de pesquisa constitui o espaço social em que se dará o desenvolvimento da pesquisa, promovendo a integração, participação e envolvimento dos sujeitos. É o cuidado na elaboração desse espaço que garantirá o sucesso do desenvolvimento da pesquisa, em que os sujeitos sentir-se-ão à vontade para se expressarem, além de possibilitar que o pesquisador adquira confiança e se familiarize com esses sujeitos e com o contexto da pesquisa.

Por meio de instrumentos empíricos variados utilizados nesse processo de pesquisa é que se pode apreender as expressões dos sujeitos investigados, possibilitando o levantamento de indicadores de sentidos subjetivos e a organização de categorias para a construção e a análise das informações. Martínez, Conceição e Pereira (2016) destacam que os indicadores são

\footnotetext{
7 “O teórico não se reduz às teorias que constituem fontes de saber preexistentes em relação ao processo de investigação, mas ao que está referido, de forma muito particular, aos processos de construção intelectual que vão acompanhando a investigação. $O$ teórico se expressa em uma processualidade que tem em seu centro a atividade pensante e construtiva do investigador." (Tradução nossa).
} 
diferentes dos dados, pois correspondem apenas às informações que possuem sentido com base na interpretação que o pesquisador faz delas. As autoras apontam que esses indicadores geram hipóteses que podem não possuir relação direta ao conteúdo das informações coletadas separadamente, mas que se definem pela relação estabelecida entre elas no contexto do sujeito e no processo de construção e interpretação do pesquisador.

La concepción de indicador y no de dato permite la definición de una nueva opción en la construcción del conocimiento. Es importante destacar que la investigación cualitativa basada en la Epistemología Cualitativa no está dirigida esencialmente a la producción de resultados finales que pueden ser tomados como definitivos acerca del objeto en estudio, sino a la producción de nuevos momentos teóricos que se integran organicamente en el proceso general de construcción de conocimientos sobre el problema en foco. ${ }^{8}$ (MARTÍNEZ, CONCEIÇÃO e PEREIRA, 2016, p. 24).

Destarte, para González Rey (2006), a construção do conhecimento não se dá de uma forma preestabelecida, mas é orientada pela reflexão do pesquisador ao longo do processo, confrontando as informações coletadas nos momentos empíricos com a representação teórica que possui do objeto em estudo, construindo e reconstruindo, assim, continuamente, seu próprio modelo teórico. As expressões da linguagem e as emoções apreendidas nos momentos empíricos constituem os indicadores da investigação, organizados em categorias, cujas análises resultam na formulação de hipóteses que, no percurso de sua confirmação por meio do contínuo fluxo reflexivo, vão fazendo emergir os sentidos subjetivos relacionados ao tema de pesquisa.

Assim, a epistemologia qualitativa de González Rey se configura como uma eficiente proposta epistemológica e metodológica para o

\footnotetext{
8 “A concepção de indicador e não de dado permite a definição de uma nova opção na construção do conhecimento. É importante destacar que a investigação qualitativa baseada na Epistemologia Qualitativa não está dirigida essencialmente à produção de resultados finais que podem ser tomados como definitivos acerca do objeto em estudo, mas à produção de novos momentos teóricos que se integram organicamente no processo geral de construção de conhecimentos sobre o problema em foco." (Tradução nossa).
} 
desenvolvimento de pesquisas de abordagem qualitativa, sinalizando que a construção do conhecimento se dá através da participação ativa do pesquisador no processo de investigação e, associando à teoria da subjetividade, mostrando a inexistência da neutralidade científica, a inevitável implicação do investigador e a impossibilidade de formulação de resultados finais com teorias absolutas sobre quaisquer assuntos.

\section{A fenomenologia e o método fenomenológico}

Nascida no século XX, a fenomenologia constitui-se como um grande movimento filosófico que em muito tem contribuído para o desenvolvimento de pesquisas empíricas de abordagem qualitativa, em especial no campo da Psicologia e da Saúde, principalmente quando se pretende enfatizar a experiência de vida das pessoas. Ademais, a fenomenologia buscava colaborar com o aprimoramento das ciências ditas positivas, físicas e naturais, por meio de seu método crítico e rigoroso de volta às essências dos fenômenos.

Segundo Moreira (2002), esse movimento filosófico tem início com Edmund Husserl (1859-1938), a partir da publicação do livro Investigações Lógicas, que objetivava a reconstrução da Filosofia como uma ciência rigorosa por meio da fenomenologia, procurando afastar as especulações abstratas e se atentar às "próprias coisas", enfatizando a experiência vivida. Nesse sentido, a fenomenologia seria capaz de oferecer um método filosófico isento de pressuposições, tendo como meta a descrição dos fenômenos como efetivamente aparecem à consciência.

Dessa forma, não irá pressupor nada, nem o senso comum, nem o mundo natural, nem as descobertas e as teorias da ciência. Ficará postada antes de qualquer crença e de qualquer juízo, para explorar simplesmente o fenômeno tal como é dado à consciência. O termo fenomenologia deriva de duas outras palavras de raiz grega: phainomenon (aquilo que se mostra a partir de si mesmo) e logos (ciência ou estudo). Portanto, etimologicamente, Fenomenologia é o estudo ou a ciência do fenômeno, sendo que por fenômeno, em seu 
sentido mais genérico, entende-se tudo o que aparece, que se manifesta ou se revela por si mesmo. (MOREIRA, 2002, p. 63).

De acordo com Moreira (2002), a compreensão de percepção é fundamental para o entendimento de fenômeno. Para ele, a percepção é um processo que se dá através dos sentidos, cuja estimulação é transformada em experiência organizada. Por sua vez, após os estímulos sensoriais, o fenômeno é a percepção que se torna visível à nossa consciência, sendo, assim, o fenômeno puro. Dessa forma, a fenomenologia busca a apreensão, a análise e a descrição dos fenômenos como se manifestam na consciência, sendo uma "volta às coisas mesmas" nas próprias palavras de Husserl. Assim, os fenômenos se referem a todas as maneiras de estar consciente de alguma coisa, incluindo não somente os objetos físicos, mas também os desejos, os sentimentos, as imaginações e os pensamentos.

Diversos conceitos são encontrados para a fenomenologia em vários estudos da área: movimento filosófico, escola de filosofia, método filosófico, descrição e estudo das aparências e ciência. O que é comum em todas essas concepções é a procura incessante pela investigação dos fenômenos, da experiência humana da consciência, das aparências, das essências. (MOREIRA, 2002). Destarte, apesar de não ter se consagrado como ciência, a fenomenologia pode ser considerada tanto como método, quanto como movimento, sendo, segundo Moreira (2002), essa última definição bem mais extensiva.

Por isso, ao longo dos tempos muitas tendências filosóficas surgiram como ramificações da própria fenomenologia, sendo elas: a) fenomenologia descritiva, com viés reflexivo e descritivo dos fenômenos, representa o início do movimento com Husserl; b) fenomenologia realista, que objetiva a busca pelas essências universais, incluindo variados assuntos, como Ética, Antropologia e Religião, por exemplo, e as ações humanas; c) fenomenologia constitutiva, também fundamentada em Husserl, com reflexões sobre o método fenomenológico, em especial a redução fenomenológica e a redução eidética; d) fenomenologia existencial, que aborda temáticas como ação, 
desejo, conflito, opressão, finitude e morte; e) fenomenologia hermenêutica, com destaque dado ao método da interpretação. Todas essas tendências influenciaram o desenvolvimento de pesquisas empíricas nas ciências humanas e sociais, como, por exemplo, em Administração e Educação, disciplinas aplicadas. (MOREIRA, 2002).

No tocante ao método fenomenológico, Moreira (2002) ressalta que ele se apresenta mais como uma doutrina do que como um conjunto de procedimentos de pesquisa, uma vez que qualquer doutrina pode originar um método e qualquer método deve estar fundamentado em uma doutrina. Por essa razão, muitas vezes os termos Fenomenologia, Filosofia Fenomenológica e Método Fenomenológico são usados por muitos autores como sinônimos. Todavia, podemos destacar dois procedimentos da fenomenologia que compõe o método fenomenológico na pesquisa, são eles: a redução fenomenológica (ou transcendental) e a redução eidética, propostas por Husserl.

A redução fenomenológica corresponde ao método de investigação desenvolvido por Husserl em que se realiza a suspensão das crenças, opiniões e tradições com vistas à análise dos fenômenos tais como se apresentam à consciência. Também denominada de epoqué, palavra grega que para a filosofia significa "suspensão de julgamento", a redução fenomenológica possibilita colocar a realidade entre parênteses, examinando o fenômeno sem a interferência do mundo natural para descobrir como o conhecimento se releva à consciência, chegando, assim, à sua essência, à sua unidade de sentido. Quanto à nomenclatura transcendental, Moreira (2002) sinaliza que ela deriva do latim transcendere, que significa "ir além", "ultrapassar". Nesse sentido, a redução fenomenológica ou transcendental busca a essência dos conteúdos da consciência, suas vivências intencionais, indo além, ultrapassando o mundo das aparências, as atitudes naturais e ingênuas, o senso comum.

Por sua vez, a redução eidética diz respeito à captação e apreensão das estruturas amplas e inalteráveis dos fenômenos. Para tanto, é preciso separar 
as regularidades de dado fenômeno para encontrar suas particularidades, suas essências.

A redução eidética é a forma pela qual o filósofo se move da consciência de objetos individuais e concretos para o domínio transempírico, das essências puras, atingindo a intuição do eidos (a apalavra eidos significa "forma" em grego) de uma coisa, ou seja, do que existe em sua estrutura essencial e invariável, separado de tudo o que lhe é contingente ou acidental. Eidos é o princípio ou estrutura necessária da coisa. (MOREIRA, 2002, p. 89)

Para a realização da redução eidética é necessário o uso do método de variação livre, que consiste em observar os diversos aspectos que compõem um dado fenômeno. Retirando-se as características convencionais, as variações que surgem compõem o próprio eidos, a essência do fenômeno. Para que as essências sejas descobertas, é primordial realizar a depuração do fenômeno, retirando dele tudo o que não é essencial. Pensa-se no fenômeno, tenta-se retirar dele as características que não o descaracterizam, e os aspectos que forem impossíveis de serem retirados, pois são essenciais para a sua existência, compõem o eidos, a estrutura do fenômeno. Como ressalta Moreira (2002), a essência de um fenômeno é definida pela "“consciência de impossibilidade', ou seja, como aquilo que é impossível à consciência pensar de outro modo, ou, então, como aquilo sem o que a coisa ou o fenômeno é impensável” (p. 91).

Moreira (2002) chama a atenção para o fato de que o método fenomenológico possui diversas variantes, o que diferencia de autor para autor. Dessa forma, muitos métodos fenomenológicos, como o de Van Kaam, o de Colaizzi, o de Sanders e o de Giorgi possuem características bem semelhantes, como a descoberta, descrição e análise das essências dos fenômenos na consciência e a configuração de unidades de sentido desses fenômenos, porém algumas delas não utilizam as denominações redução fenomenológica e redução eidética, apesar de seguirem de forma bem similar suas propostas. Como instrumentos de coletas de dados, muitos desses 
métodos fazem uso de entrevistas, descrições por escrito de experiências pelos próprios sujeitos, relatos autobiográficos realizados de forma oral ou escrita, observações participantes, entre outros.

Afora, muitas dificuldades e questionamentos surgem sobre a transposição do método fenomenológico da filosofia para a pesquisa empírica. Alguns desses questionamentos situam-se sobre a possibilidade de efetivamente conhecer a consciência, o mundo dos outros, atingir as essências por meio de seus relatos. Além disso, Moreira (2002) enfatiza que a Filosofia e a pesquisa empírica são áreas de reflexão distintas, uma vez que esta última possui um maior caráter de ação e interação com objetos e pessoas. Para ele, a fenomenologia é recomendada nos casos em que a pesquisa clássica não o é. Quantos aos fenômenos, seus objetos de estudo, são adequados os fenômenos humanos subjetivos, que fazem parte das experiências vivenciadas pelos sujeitos.

Para além do exposto, outros questionamentos surgem acerca da cientificidade do método fenomenológico. Sobre isso, sem apresentar uma resposta concreta para a questão, Moreira (2002) discorre que é preciso recorrer a validade interna dos métodos utilizados, que permitirá verificar com segurança a veracidade dos conhecimentos adquiridos, bem como considerar sua validade externa, examinando a possibilidade de generalização a um grande número de fenômenos. Entretanto, o autor evidencia que a validade interna muitas vezes não é suficiente para certificar a validação externa, porém é essencial para o reconhecimento da pesquisa.

Assim, a fenomenologia, como qualquer outra área da pesquisa voltada para uma abordagem qualitativa, apresenta suas dificuldades de aplicabilidade e validação, justamente devido à criticidade e à rigidez com que visam ao desenvolvimento de seus métodos, tendo em vista o reconhecimento tal qual adquirido pelas ciências positivas. Fora isso, sua grande proposta de desvelar a essência dos fenômenos como aparecem na consciência dos sujeitos por meio de suas experiências vividas é capaz de produzir um conhecimento profundo do ser humano de volta às raízes, desconsiderando quaisquer interferências, como opiniões, julgamentos, 
crenças ou outros fatores externos, ponderando apenas a relação entre o sujeito, sua consciência e o conhecimento.

\section{A pesquisa-ação na visão de Thiollent}

Nos diversos campos da produção acadêmica e científica, a pesquisa-ação vem ganhando cada vez mais espaço como método de investigação. Para Thiollent (2011), a pesquisa-ação é capaz de explicar problemas sociais e técnicos, considerados importantes cientificamente, por meio de grupos formados por pesquisadores, membros das situações-problemas investigadas e por outras pessoas que se interessam em colaborar com a resolução desses problemas ou com a procura de respostas educacionais, sociais, técnicas e/ou políticas adequadas para eles.

Nesse processo de pesquisa-ação são formulados objetivos de ação e objetivos de conhecimento, por sua vez vinculados a um amplo quadro de referências teóricas que norteiam a elaboração de conceitos e constituem as linhas de interpretação das informações coletadas durante a pesquisa. Como sinaliza Thiollent (2011), a pesquisa-ação deve ser considerada mais como um método, percurso prático da investigação, do que como uma metodologia, discussão epistemológica dos métodos. Mesmo assim, o autor optou por fazer uso da palavra metodologia no título de sua obra basilar "Metodologia da Pesquisa-Ação", que tem por objetivo discutir os principais temas metodológicos desse tipo de pesquisa.

Segundo Thiollent (2011), a pesquisa-ação muitas vezes continua a ser utilizada como sinônima da pesquisa-participante, porém as duas, apesar de possuírem algumas semelhanças, não são iguais. Para além da participação, a pesquisa-ação exige uma forma planejada de ação de cunho social, educacional, técnico ou outro, o que não encontramos na pesquisa participante, que muitas vezes se apresenta como um tipo de pesquisa apoiada na metodologia de observação participante, em que os pesquisadores interagem com os indivíduos da situação pesquisada, visando estreitar relações para serem bem aceitos pelo grupo. Assim, uma pesquisa para ser considerada como pesquisa-ação deve apresentar um planejamento de ação 
por parte dos pesquisadores e participantes na situação-problema investigada. Nesse sentido, para fins de delimitação concreta,

a pesquisa-ação é um tipo de pesquisa social com base empírica que é concebida e realizada em estreita associação com uma ação ou com a resolução de um problema coletivo e no qual os pesquisadores e os participantes representativos da situação ou do problema estão envolvidos de modo cooperativo ou participativo. (THIOLLENT, 2011, p. 20).

A pesquisa-ação exige que pesquisadores e demais pessoas envolvidas na situação de pesquisa assumam uma postura ativa, participativa e interativa. Essa postura ativa deve ser, acima de tudo, característica principal dos pesquisadores, os quais devem apreciar os problemas e acompanhar e avaliar as ações formuladas em consequência deles. Ademais, é importante destacar que o objeto de investigação na pesquisa-ação não são as pessoas, mas a situação-problema vivenciada por elas.

Quanto aos objetivos desse tipo de pesquisa, vemos que eles não se resumem apenas em resolver o problema investigado, mas pelo menos esclarecê-lo. Por essa razão, Thiollent (2011) classifica os objetivos da pesquisa-ação como práticos e de conhecimento. Os objetivos práticos dizem respeito à análise do problema investigado e formulação de propostas de ações para sua resolução, tendo em vista a transformação da situação inicialmente encontrada. Os objetivos de conhecimento, por sua vez, são aqueles que se destinam à obtenção de informações acerca da situação investigada.

Consoante Thiollent (2011), a pesquisa-ação não está limitada somente a uma forma de ação, ela busca também possibilitar o aumento do conhecimento dos pesquisadores e do conhecimento ou "nível de consciência" dos indivíduos envolvidos no contexto da pesquisa. Além disso, o autor sinaliza que o conhecimento produzido pela pesquisa-ação não é apenas útil para os envolvidos na pesquisa, é um conhecimento que pode ser utilizado para generalizações parciais, bem como servir de base para novos 
estudos de aprofundamento. Portanto, os objetivos da pesquisa-ação podem ser considerados em três aspectos: resolução dos problemas, tomada de consciência e produção de conhecimento. (THIOLLENT, 2011).

Com relação à estrutura de raciocínio da pesquisa-ação, Thiollent (2011) esclarece que toda pesquisa busca informações, estabelece e articula conceitos, analisa e discute os resultados, produz generalizações etc., o que não é diferente com a pesquisa-ação. Entretanto, optando por uma forma de raciocínio alternativa, muitas vezes oposta à lógica formal pretendida pelas ciências positivas, a pesquisa-ação percorre o caminho do processo dialógico e da abordagem argumentativa. Essa estrutura é composta por momentos de raciocínio inferenciais e processos argumentativos ou de diálogo entre os interlocutores. De acordo com Thiollent (2011), "no processo investigativo, a argumentação se manifesta de modo particularmente significativo no decorrer das deliberações relativas à interpretação dos fatos, das informações ou das ações dos diferentes atores da situação (p. 36). Na pesquisa-ação o processo argumentativo se desenrola na colocação dos problemas a serem investigados, na busca de soluções e explicações apresentadas pelos pesquisadores e discutidas com os participantes, nas deliberações acerca dos meios de ação e na avaliação dos resultados encontrados. Em síntese, a forma de raciocínio da pesquisa-ação se concentra nas situações de discussão e de argumentação entre pesquisadores e participantes.

Um outro aspecto diferenciado da pesquisa-ação é a formulação de hipóteses e sua respectiva comprovação. Thiollent (2011) frisa que a pesquisa-ação não trabalha com hipóteses formuladas de forma rígida, mas com diretrizes (instruções) relacionadas à maneira de examinar os problemas diagnosticados no contexto investigado e às formas de ação. Isso não quer dizer que o raciocínio hipotético seja dispensado na pesquisa-ação, contudo é apresentado com maior flexibilidade, formulando, assim, suposições, quasehipóteses. São essas diretrizes que possibilitam aos pesquisadores a organização do pensamento, a procura de informações relevantes e a formulação de argumentações necessárias para refutá-las ou corroborá-las. Thiollent (2011) considera que as hipóteses, formuladas nos princípios do 
experimentalismo, pressupõem testes repetitivos para evidenciar suas regularidades, o que não é possível realizar com a pesquisa de caráter social, cujos fenômenos não apresentam uma exata repetitividade, além do fato de que o pesquisador não apresenta neutralidade no contex to investigado.

Na pesquisa social de abordagem qualitativa, e não especificamente no tipo de pesquisa-ação, é possível observar dois níveis relativos ao problema de generalização: o dos pesquisadores e o dos participantes. Os primeiros formulam generalizações mais ou menos teóricas a partir dos aspectos das situações pesquisadas. Já os últimos fazem generalizações menos abstratas com base nos conceitos que lhes são conhecidos. Diante disso, os pesquisadores devem identificar e contrapor as generalizações teóricas com as generalizações populares, a fim de descobrir incompreensões e formular novas propostas de diálogos e de modificações nas maneiras de pensar certos problemas. No específico às inferências generalizantes, Thiollent (2011) ressalta que os pesquisadores precisam assinalar os defeitos da generalização que busca, a partir de poucas informações localizadas, formular conclusões para o resto da população ou do universo. Para o autor, no caso da pesquisaação, as generalizações superiores podem ser dispensadas no que diz respeito ao problema pesquisado. Ao contrário, a partir das discussões dos resultados, generalizações parciais podem ser formuladas de forma progressiva, levando em conta os resultados de outras pesquisas realizadas em locais diversos.

Com referência à organização da pesquisa-ação, Thiollent (2011) evidencia como uma de suas características principais a flexibilidade. De acordo com o autor, a pesquisa-ação é bastante flexível e, diferentemente de outros tipos de pesquisa, não segue uma estrutura bem rígida e definitiva, mas vai se estruturando e se adaptando às diversas circunstâncias ao longo do seu desenvolvimento. Entretanto, Thiollent (2011) apresenta algumas fases da pesquisa-ação que, necessariamente, não precisam ser concebidas na ordem em que as apresenta, chamando a atenção especialmente para o ponto de partida e o ponto de chegada, tendo em vista que as fases intermediárias podem ser reorganizadas a qualquer instante. 
O primeiro momento elencado pelo autor refere-se à fase exploratória da pesquisa, cuja finalidade consiste em explorar o campo de pesquisa e conhecer os sujeitos envolvidos, suas características, expectativas, problemas enfrentados e possíveis ações já desenvolvidas. Para Thiollent (2011), esse primeiro contato é substancial para o desenvolvimento das estratégias metodológicas a serem planejadas e colocadas em prática. Realizado esse diagnóstico inicial, tem-se a seguir a delimitação do tema da pesquisa, que corresponde à especificação do problema prático e da área do conhecimento a serem investigados. Thiollent (2011) chama a atenção para o fato de que a delimitação do tema deve ser realizada em discussão com os sujeitos participantes, pois eles não podem participar de uma pesquisa-ação cujo tema não corresponda aos seus anseios. O próximo passo, a colocação dos problemas, refere-se à formulação da problemática a ser investiga dentro de um campo teórico e prático. Para o autor, em pesquisa social aplicada, os problemas são de início de ordem prática, e os pesquisadores e participantes buscam soluções ou respostas para o problema, além de almejar transformações quando possíveis.

Realizado o diagnóstico inicial e delimitados o tema e o problema, segue-se para o lugar da teoria na pesquisa-ação. O projeto de pesquisa-ação deve ser alicerçado em um amplo quadro de referências teóricas. A função da teoria, segundo Thiollent (2011), incide na formulação das diretrizes (quasehipóteses) que orientarão o desenvolvimento da pesquisa e a interpretação dos dados coletados. E é mediante as diretrizes formuladas, que os pesquisadores poderão escolher as técnicas de pesquisas mais adequadas, destacando-se, entre as muitas possíveis, as técnicas de coleta em grupo. Thiollent (2011) aponta a realização de seminário como uma técnica para analisar, discutir questões e determinar os caminhos da investigação. Nesse seminário devem ser constituídos e coordenados os grupos de estudo e equipes de pesquisa. Por sua vez, a coleta de dados é controlada pelo seminário central e se dá em grande parte por meio de grupos de observação, com a utilização de técnicas de entrevista coletiva e entrevista individual, podendo ser também utilizados outros instrumentos, como questionários, diários de campo, história de vida, 
entre outros. Os dados coletados voltam para o seminário central, onde são discutidos e analisados. Para Thiollent (2011), todos esses aspectos da pesquisa-ação devem ser planejados, portanto a elaboração de um plano de ação representa uma exigência fundamental para que a pesquisa se configure como "forma de ação planejada, objeto de análise, deliberação e avaliação" (p.79).

Ademais, Thiollent (2011) menciona um aspecto bastante contraditório na pesquisa-ação, que se refere à delimitação de uma amostragem para que sejam aplicados os referidos instrumentos de coleta de dados. De acordo com ele, muitos partidários da pesquisa-ação reafirmam a ideia de que ela seja necessariamente realizada com todo o conjunto da população investigada para que possa cumprir efetivamente o seu objetivo. Porém, para Thiollent (2011), quando a população é muito grande, pode-se optar pela realização de uma amostragem. Assim, "a pesquisa é efetuada dentro de um pequeno número de unidades (pessoas ou outras) que é estaticamente representativo do conjunto da população" (p.71). Além disso, pode-se decidir pela realização de uma amostragem por representatividade qualitativa, em que algumas pessoas são escolhidas levando em consideração sua representatividade social dentro do contexto investigado.

Outro importante aspecto destacado por Thiollent (2011) é o grande papel da aprendizagem na vida dos pesquisadores e sujeitos participantes de uma pesquisa-ação. Independentemente do tipo de amostragem e das técnicas utilizadas para coleta de dados, todos os envolvidos possuem oportunidades de se aprimorarem e construírem conhecimentos. Para Thiollent (2011), essa perspectiva de aprendizagem é bastante evidenciada nos contextos educacionais, contudo também pode ser observada em outras áreas, como na saúde, na comunicação, na tecnologia, no serviço social, em organizações empresariais, entre outros. Dessa forma, a aprendizagem é concebida como resultado das exigências da ação em torno da qual se desenvolve a pesquisa, envolvendo discussão, circulação de informações, produção de conhecimentos, tomada de decisões, entre outras ações. 
Como ponto de chegada da pesquisa-ação, Thiollent (2011) estabelece a necessidade de divulgação externa. Essa divulgação dos resultados encontrados e das ações desenvolvidas vai além do contexto dos participantes e abrange diversos contextos externos da sociedade, podendo ser feita por meio de discussão de trabalhos em conferências, congressos, palestras, entre outras modalidades. Assim, a divulgação dos resultados de uma pesquisaação não deve ser utilizada como "propaganda", mas como forma de fazer com que os caminhos percorridos e resultados obtidos se tornem conhecidos e possam dar origem a um novo período de investigações e ações por parte de outros pesquisadores. (THIOLLENT, 2011).

Enfim, como qualquer outro tipo de pesquisa, a pesquisa-ação fecha um ciclo que precisa ser bem planejado inicialmente, apresentando suas etapas de forma flexível para que possa se adequar a diversas situações e contextos de pesquisa, tendo como enfoque a inter-relação entre conhecimento e ação, numa perspectiva de interação, participação e colaboração entre todos os envolvidos no processo de investigação.

\section{Diálogos possíveis}

Dadas as breves revisões teóricas apresentadas, dizemos que é possível apontar alguns elementos de concordância e outros de discordância entre a epistemologia qualitativa de González Rey, a fenomenologia na perspectiva de Moreira e a pesquisa-ação na proposta de Thiollent, como veremos a seguir.

Num primeiro momento, observamos que tanto a epistemologia qualitativa, quanto a fenomenologia e a pesquisa-ação são caminhos metodológicos de abordagem qualitativa para as investigações realizadas dentro dos campos das ciências humanas e sociais. São nítidas em todas essas categorias a busca por novas concepções de pesquisa e a utilização de novos métodos e instrumentos que possibilitem um processo mais amplo de investigação, afastando-se dos domínios das ciências positivas e de seus métodos considerados infalíveis e absolutos. Pelo contrário, as propostas de pesquisa aqui elucidadas concebem o processo de investigação como flexível, 
cujos métodos e instrumentos podem se adequar às situações, aos objetos e sujeitos da pesquisa. Ademais, os conhecimentos produzidos não podem ser considerados estanques, todavia servem de suporte para o início de novas investigações e produção de novos conhecimentos.

Como uma resposta à objetividade e à neutralidade pretendida pelas ciências positivas, a epistemologia qualitativa de González Rey surge como uma proposta séria para o estudo da subjetividade e dos fenômenos complexos a ela relacionados, principalmente no campo da Psicologia. Semelhantemente, a fenomenologia, segundo Moreira (2002), pretende investigar os fenômenos em sua essência, as experiências vivenciadas como se apresentam à consciência, a busca da subjetividade transcendental, o que corresponde ao estudo profundo de fenômenos subjetivos humanos na produção do conhecimento, realizado, em especial nas áreas da Psicologia e da Saúde. A pesquisa-ação, por sua vez, não faz referência específica à subjetividade, mas se apresenta como um método alternativo para a pesquisa qualitativa em ciências humanas e sociais, trabalhando na perspectiva da inter-relação entre o conhecimento e a ação, envolvendo de forma interativa pesquisadores, sujeitos pesquisados e demais participantes na produção do conhecimento e em uma possível transformação da situação investigada.

No tocante às interferências do contexto social, observamos que a epistemologia qualitativa desenvolve seu estudo acerca da subjetividade considerando sua íntima relação com o momento social, em que o indivíduo está comprometido com suas práticas sociais, reflexões e produção de sentidos subjetivos. Esses sentidos subjetivos produzidos nos variados espaços sociais afetam outros ambientes dos quais participa o sujeito, sendo ele também afetado pela subjetividade existente nesses espaços. Do mesmo modo, a influência do contexto social também se faz presente na pesquisaação, cuja proposta enfatiza o estudo de diferentes formas de ação dentro de um ponto de vista sociológico, considerando os aspectos estruturais da realidade social, as interações, os fatores sociopolíticos, entre outros aspectos. Como aponta Thiollent (2011), a pesquisa-ação não despreza a realidade psicológica e existencial, como também não é pertinente para um estudo 
macrossocial, trabalhando, entretanto, numa faixa intermediária, como "instrumento de trabalho e de investigação com grupos, instituições, coletividades de pequeno ou médio porte" (p.15). De forma contrária, a fenomenologia não nega a existência da influência dos contextos sociais, porém promove a sua suspensão. Nesse sentido, o mundo exterior é colocado em parênteses, pois para a fenomenologia o que importa é como o conhecimento é revelado à consciência, desconsiderando todas as interferências exteriores, como opiniões, crenças, realizando, assim a radical suspensão do mundo natural.

Quanto à natureza epistemológica e metodológica, consideramos que a epistemologia qualitativa e a fenomenologia se apresentam tanto como uma abordagem metodológica, em que se discutem ampla e epistemologicamente pressupostos e caminhos da pesquisa, quanto como método, cujas etapas e instrumentos de investigação são bem delimitados em seu processo. Diferentemente, a pesquisa-ação, como discorre Thiollent (2011), não é considerada como metodologia, mas como método ou uma estratégia de pesquisa composta por vários métodos e técnicas, que apresentam dimensões coletiva e interativa para investigação, coleta de dados, registro, processamento, interpretação, análise e exposição dos resultados.

De forma bem específica, podemos comparar duas etapas referentes, respectivamente, à epistemologia qualitativa e à fenomenologia. São elas: a produção de indicadores de sentidos subjetivos e a construção de unidades de sentidos. Os indicadores de sentidos subjetivos, na epistemologia qualitativa, segundo González Rey (2006), correspondem à produção e análise de informações a partir da captação das emoções e expressões dos sujeitos pesquisados. Para ele, os sentidos subjetivos se encontram na qualidade das informações, no posicionamento de uma palavra no texto, nos tipos de expressão, nas significações dadas a certos conceitos, entre outros elementos. De forma semelhante, encontramos as unidades de sentido, que dizem respeito aos temas, às essências presentes nas descrições feitas dos fenômenos (as experiências vivenciadas pelos sujeitos) a partir das intenções do pesquisador. A construção das unidades de sentido faz parte do processo de 
redução fenomenológica ou transcendental (epoqué) como uma das etapas do método fenomenológico proposto por Husserl. As diferenças entre os indicadores de sentidos subjetivos e as unidades de sentido estão nas considerações das interferências dos espaços sociais na análise dos fenômenos subjetivos. Os indicadores de sentidos subjetivos na epistemologia qualitativa, segundo González Rey (2006), são construídos considerando a subjetividade sob um enfoque histórico-cultural, na dialética entre o individual e o social. Já as unidades de sentido na fenomenologia, segundo Moreira (2002) são identificadas a partir da suspensão do mundo natural, objetivando-se chegar às essências dos fenômenos afastando-os das influências do social.

Com relação aos instrumentos de coletas de dados, observamos que alguns deles são utilizados pelos três tipos de pesquisa aqui mencionados. Entre eles podemos citar, por exemplo, a entrevista, o questionário e o relato, que podem fazer tanto parte do processo de busca de essências da fenomenologia, da construção de sentidos subjetivos e das categorias de análise da epistemologia qualitativa e das etapas de diagnóstico, de acompanhamento e de avaliação de todo o processo da pesquisa-ação. É importante destacar que na pesquisa-ação, de forma específica, são muito privilegiados os instrumentos coletivos, objetivando o conhecimento de uma realidade grupal e o planejamento e execução de ações tendo em vista essa coletividade. Como exemplos, temos o seminário, os grupos de observação, as entrevistas coletivas, o sociodrama, os diários de campo, entre outros. Isso não quer dizer que a epistemologia qualitativa e a fenomenologia também não possam se utilizar desses instrumentos. A depender do objeto, objetivos, sujeitos e campo de pesquisa, os instrumentos mencionados podem ser totalmente adequados.

É fundamental discorrer, ainda, acerca da importância do diálogo como característica partilhada entre a epistemologia qualitativa, a fenomenologia e a pesquisa-ação. Todas elas tendem a valorizar o processo dialógico como um dos meios de obterem as informações de que necessitam para análise e a partir delas realizarem novas descobertas e produzirem conhecimentos. $\mathrm{Na}$ 
fenomenologia, por exemplo, por meio do diálogo e das descrições das experiências realizadas pelos próprios sujeitos é possível identificar as unidades de sentido para compreensão das essências dos fenômenos. González Rey (2006) destaca que o diálogo é a estratégia principal a partir da qual se organiza toda a investigação na epistemologia qualitativa, sendo a comunicação um campo de produção ativa dos sujeitos. Na pesquisa-ação, o diálogo perpassa todos os momentos do processo, sendo uma ferramenta essencialmente construtiva para a busca conjunta de soluções para os problemas da situação investigada.

Por fim, mais um ponto em comum encontrado entre a epistemologia qualitativa, a fenomenologia e a pesquisa-ação é a reflexibilidade presente no percurso do desenvolvimento da pesquisa. Para Thiollent (2011), a pesquisaação possibilita a reflexão dos pesquisadores, sujeitos pesquisados e demais participantes em todo o processo, desde a fase exploratória, a articulação com a teoria, o planejamento das ações e a avaliação dos resultados, fazendo com que todos os envolvidos possam se ver como sujeitos ativos na construção do conhecimento. A pesquisa com caráter fenomenológico também exige uma reflexão exaustiva para a busca da essência dos fenômenos investigados, principalmente na realização da fenomenologia hermenêutica, que corresponde à fase final de interpretação do sentido dos fenômenos. $\mathrm{Na}$ epistemologia qualitativa, tendo em vista seu próprio caráter construtivointerpretativo, a reflexibilidade compõe uma de suas principais características, visto que, como assinala González Rey (2006), é a partir das ideias, das reflexões e das trocas informais que acontecem durante a investigação que os pesquisadores produzem sentido.

Enfim, observamos que a epistemologia qualitativa, a fenomenologia e a pesquisa-ação, por se tratarem de categorias de pesquisa de abordagem qualitativa nas ciências humanas e sociais, apresentam certas semelhanças, aproximando-se em algumas características e se diferenciando por outras, considerando as próprias especificidades de investigação, os objetos de pesquisa, os métodos e técnicas empregados e as formas de análise efetuadas. 


\section{Considerações finais}

As pesquisas de abordagem qualitativa desenvolveram-se a partir do século XIX como uma clara oposição às metodologias, métodos e instrumentos utilizados pelas ciências positivas e naturais, combatendo, assim, a pretensão de construção de um conhecimento objetivo, que se foca apenas na preservação do objeto de pesquisa, e neutro, que desconsidera a subjetividade do pesquisador e dos demais atores do processo de pesquisa.

Como características principais de grande parte das pesquisas qualitativas, podemos citar: a concepção de realidade social como construção de significados, o enfoque no processo e na reflexão, a formulação de condições objetivas a partir de significados subjetivos, o caráter comunicativo da realidade social e a possibilidade de reformulação dos resultados como novos pontos de partida. Outras características gerais também são identificadas, como: a compreensão como princípio do conhecimento, a descoberta e a construção de teorias e a preferência pelo material textual.

A pesquisa qualitativa analisa o objeto de estudo em sua historicidade e toma sempre como ponto de partida a formulação de um problema. Além disso, utiliza os acontecimentos e conhecimentos cotidianos como elementos para interpretação dos dados, promovendo contextualidade, reflexão contínua e interação dinâmica, características essas dificilmente encontradas na pesquisa quantitativa. Fora isso, observamos na pesquisa qualitativa a aceitação de influências de crenças e valores sobre a teoria, na escolha dos métodos e na forma de interpretação do pesquisador.

Possibilitando concepções mais pluralistas e interpretativas, considerando aspectos subjetivos, sociais, históricos e culturais da realidade, novas formas de investigação passaram a integrar o processo de pesquisa, como a hermenêutica, a fenomenologia, a etnografia, a metodologia da pesquisa participativa, o estudo de caso, entre outros, fazendo o uso de instrumentos de coleta de dados diversos, como entrevistas, questionários, testes, grupos de discussão, relatos biográficos, análise de documentos e conversações, etc. 
Neste estudo, discorremos sobre os pressupostos e particularidades da epistemologia qualitativa, da fenomenologia e da pesquisa-ação, como novas alternativas de pesquisa qualitativa para o campo das ciências humanas e sociais. Procuramos evidenciar algumas semelhanças e diferenças existentes entre essas categorias de pesquisa, evidenciando seus objetos de estudos, contextos de investigação, valorização e interferência do subjetivo e da realidade social, escolha de instrumentos de coleta e forma de tratamento dos dados, entre outros aspectos. Verificamos, que apesar de algumas divergências encontradas, todas essas tipologias de pesquisa caminham para a construção de um processo de investigação muito mais interpretativo e reflexivo, sendo flexíveis e adaptáveis, não utilizando instrumentos padronizados e reforçando a ideia de que cada problema de pesquisa demanda seus próprios procedimentos e instrumentos.

Assim, a epistemologia qualitativa, a fenomenologia e a pesquisa-ação promovem a quebra de paradigmas tradicionais de pesquisa, em especial no campo das ciências positivas, e possibilitam o surgimento de paradigmas modernos, com novas técnicas e instrumentos variados, considerando, cada uma a seu modo, a inter-relação entre objetividade e subjetividade no decurso da pesquisa, atentando, ainda, para a influência dos contextos histórico, social e cultural no processo de interpretação da realidade investigada e na produção do conhecimento científico.

\section{Referências}

GAMBOA, Silvio Sánchez. Pesquisa em Educação: Métodos e Epistemologias. Chapecó: Argos, 2007.

JAPIASSU, Hilton. Nascimento e Morte das Ciências Humanas. Editora Francisco Alves, 1978.

MÁRTINEZ, Albertina Mitjáns; CONCEIÇÃO, Maria Inês Gandolfo; PEREIRA, Alciane Barbosa Macedo. Epistemología cualitaiva de González Rey: una forma diferente de análisis de "datos". In: Revista Tecnia, v.1, n.1, 2016. 
Disponível em: $<$ revistas.ifg.edu.br/tecnia/article/download/3/6>. Acesso em 20 de Abril de 2017.

MOREIRA, Daniel Augusto. O método fenomenológico na pesquisa. São Paulo: Pioneira Thomson, 2002.

REY, Fernando Luís González. Sujeito e Subjetividade: uma aproximação históricocultural. São Paulo: Thomson Learning, 2003.

. Investigación cualitativa e subjetividad: los procesos de construcción de la información. México DF: McGraw-Hill, 2006.

SANFORD, Fernando (1899). The scientific method and its limitations. Disponível em:

$<$ http://web.stanford.edu/dept/spec_coll/uarch/commencement/SC1020_1 899. pdf>. Acesso em 12/05/2017.

THIOLLENT, Michel. Metodologia da pesquisa-ação. São Paulo: Cortez, 2011. 